\title{
Physical Activity: The Pill Not Taken
}

\author{
Thomas L. McKenzie \\ San Diego State University
}

\begin{abstract}
This paper summarizes the first-ever IOHSK distinguished lecture. It briefly describes Dr. McKenzie's lengthy research career, identifies the importance of physical activity to public health, emphasizes the need for research and program collaborations, and highlights systematic observation as a tool for generating contextual information on the occurrence of physical activity. It concludes with suggestions about how IOHSK members can become more involved in physical activity promotion.
\end{abstract}

Keywords: research, physical activity, systematic observation, collaborations

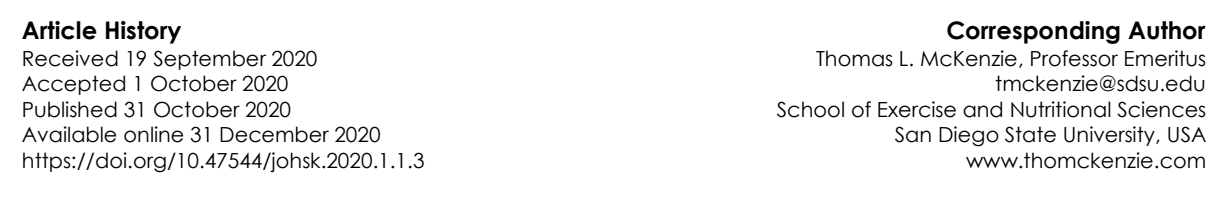

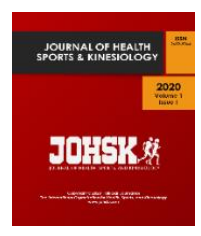

\section{Physical Activity: The Pill Not Taken}

It is a tremendous honor to have been selected to deliver the first-ever distinguished lecture for the International Organization for Health, Sport, and Kinesiology (IOHSK). I want to extend special thanks to Dr. Hosung So and to the Organizing Committee for the opportunity to share my background at such a notable event.

I have had a long, diverse background that initially included working with schools (i.e., teacher, administrator, sport coach, athletic director, researcher), obese individuals in summer residential camping settings (McKenzie, 1986), and Olympic-level athletes (Gipson, McKenzie, \& Lowe, 1989). More recently, I began to focus my work on public health, and I have been fortunate to have been able to travel to 64 countries and visit schools, community centers, and parks there.

Physical activity (PA) is a major part of the three facets of the IOHSK (i.e., health, sport, kinesiology), and I am grateful for my extensive background in physical education (PE), sport, and public health. With concern for the current global low levels of PA, I titled my paper, Physical Activity: The Pill Not Taken, and in it I briefly highlight some of our studies related to investigating PA and getting people to be more active. As background, I believe: (a) PA is a behavior--an action that is positively associated with both physical and mental health, (b) PA is not random, but is contextual and occurs differentially among specific settings; (c) and evidence matters. All three suggest the need for IOHSK professionals to generate practical data to in order assess and improve their programs.

I will frequently use the word "we" because I believe in the importance of collaborative works. They bring together people with the different interests and expertise, both which are essential to program development and large-scale research. For four decades I have been fortunate to have had numerous national and international research partners and collaborators.

Journal of Health Sports \& Kinesiology | ISSN 2692-9864 | www.johsk.com 
| 2020 | Volume 1 | Issue 1 | The Journal of Health, Sports, and Kinesiology |

\section{Physical Activity and Health}

Regular PA can help prevent and treat noncommunicable diseases such as heart disease, stroke, diabetes, and breast and colon cancer. As well, it can help prevent hypertension, overweight, and obesity and improve mental health, quality of life and well-being (WHO, 2018). Nonetheless, sedentary living (at 6\%) has been identified as the fourth leading risk factor for global mortality, surpassing overweight and obesity which are at 5\% (WHO, 2010). For the U.S., the first PA goals/recommendations were identified in the 1996 Surgeon General's report (USDHHS, 1996). Those recommendations have been revised several times--most recently in the Second Edition of Physical Activity Guidelines for Americans (Piercy et al., 2018). Unfortunately, over $42 \%$ of the adult population in the U.S is obese (Trust for America's Health, 2020) and the burden from physical inactivity is estimated to be between 200 and 300 thousand preventable deaths yearly (Piercy et al., 2018). Meanwhile, except for athletes and those in rigorous training, there are concerns about insufficient amounts of engagement in PA worldwide (WHO, 2018).

Most countries have PA recommendations (WHO, 2018), and similar to the U.S. (Katzmarzyk et al., 2018) many countries (Aubert et al., 2018) also periodically generate report cards for children and youths that have different indicators (e.g., overall PA, sedentary behaviors, active transportation, organized sports, health related fitness, PA among family and peers, schools, and the built environment). Such indicators make it possible to identify trends over time. As an example, Healthy People 2010 (USDHHS, 2000) has identified specific public health objectives for youth PA on U.S. school campuses, both within and outside of PE. These include the promotion of youth PA of moderate and vigorous intensities, daily PE lessons that are highly active, access to school facilities beyond the school day, and having students walk and bicycle to school. Unfortunately, the report card grade for how U.S. schools are doing relative to PA has declined from a "C minus" in 2014 to a "D minus" in 2018.

\section{Evidence Matters: Assessing Physical Activity and Its Contexts}

IOHSK professionals should be able to justify their programs, including their objectives facilities, equipment, personnel, and budgets. Meanwhile, to be successful at improving population PA (or even that of an individual), we need to first understand the characteristics (i.e., antecedents and consequences) of the settings in which PA could occur. Subsequently, generating, analyzing, and sharing data are important for assessing baseline levels of PA and program use, evaluating interventions and program changes, and advocating for program components. To do this we need to collect relevant information, not only about PA levels (e.g., frequency, duration, intensity), but also about the events that control them. Thus, we need quality assessment tools.

There are very many ways to assess PA, and each method has advantages and disadvantages. Based on pragmatism (e.g., cost, feasibility) and the goal of a particular study, I have used diverse methods (e.g., heart rate monitoring, accelerometers, self-reports). Nonetheless, my favorite method involves the use of systematic direct observation. Direct observation enables us to assess PA engagement simultaneously with detailed data on the context in which it occurs (e.g., where, when, with whom, and other relevant antecedents and consequences). The method has strong internal/face validity, is flexible, and requires low participant burden (e.g., people are not asked to recall details, wear a monitoring device, or provide a fluid sample). As well, the data can be collected in locations where other assessment tactics do not function well (e.g., in aquatic and martial arts settings). Nonetheless, systematic observation does have disadvantages, including the need for observer training and monitoring and potential subject reactivity.

We recently identified considerations for selecting observation techniques and instruments and how to train observers for using them in both structured (e.g., physical education, sport practices) and unstructured settings (e.g., recess, parks) in "Top 10 Research Questions Related to Assessing Physical Activity and Its Contexts" (McKenzie \& van der Mars, 2015) and in "Context matters: Systematic observation of place-based physical activity" (McKenzie, 2016). A brief description of three related observation systems follows. While we created them for different purposes, they have commonalities including: (a) being published and widely used; (b) having similar validated PA codes (e.g., via accelerometry, heart rate monitoring) and useful with different populations (e.g., age groupings, special needs children); (c) having cost-free protocols available to facilitate observer reliability; and (d) being well supported by both behavior analytic principles and social ecological theory.

SOFIT: System for Observing Fitness Instruction Time. SOFIT is used primarily during instructional sessions (e.g., physical education, dance, sport practices) to simultaneously assess (a) participant PA levels, (b) lesson/session/practice context (i.e., how content is delivered, including time allocated for physical fitness, motor skill development, game play, knowledge, and session management), and (c) teacher/coach behavior relative to the promotion of PA, skills, and fitness (McKenzie et al., 1991). The main focus is on individuals, and observers are paced by a visual or audible signal using an interval recording format (e.g., 10-sec observe/10-sec record). Typical

Journal of Health Sports \& Kinesiology | ISSN 2692-9864 | www.johsk.com

Page | 4 
| 2020 | Volume 1 | Issue 1 | The Journal of Health, Sports, and Kinesiology |

SOFIT outcome data include minutes and proportion of time participants spend in various postures (i.e., lying down, sitting, standing) and in walking/moderate and vigorous activity. SOFIT also provides important information on: (a) session schedule (e.g., frequency, adherence to schedule, duration of scheduled and actual session length, and number of participants), (b) session context (i.e., minutes and \% of time spent in management, instruction, fitness, skill drills, game play, and free play), and (c) instructor behavior (e.g., intervals instructors spend promoting PA, fitness, and skill engagement). SOFIT (and its adaptations) has been used widely in the USA (McKenzie \& Smith, 2017) and internationally (Smith, McKenzie, \& Hammons, 2019) in a variety of settings (e.g., preschools, sports instruction, special needs classrooms, after school programs) for over 30 years.

SOPLAY: System for Observing Play and Leisure in Youth. SOPLAY provides data on the number of participants and their PA levels in predetermined target areas. It uses a group momentary time-sampling format (i.e., a series of observation "snapshots") to record the PA level and additional characteristics of each individual (e.g., gender) in an area using systematic scanning (McKenzie, 2016; McKenzie et al., 2000). Separate scans are typically made for males and females with entries for area contextual characteristics being recorded simultaneously (e.g., whether they are accessible and usable, and whether or not supervision, organized activities, and loose equipment are being provided). These characteristics are observed because they impact the number of participants and their PA levels within a space and they can be modified via policy and programming changes.

SOPARC: System for Observing Physical Activity and Leisure Time in Communities. SOPARC expands SOPLAY to include the recording of the age (i.e., child, teen, adult, senior) and race/ethnicity (e.g., white, black, Latino, other) grouping of each area user (McKenzie et al., 2006). It is typically employed to investigate park and recreation areas, including assessing community/school shared use of facilities (Evensen et al., 2016; McKenzie, 2016; McKenzie \& van der Mars, 2015). SOPLAY/SOPARC have been widely used internationally (Evenson, et al., 2016). Their typical outcome data include the number and proportion of participants in an area overall by variable of interest (e.g., gender, age grouping) as well as the frequency and the proportion of times during observation visits that a facility was accessible, usable, supervised, and had organized activities and loose equipment available. Energy expenditure rates for areas (e.g., MET values) can be calculated (using number of people present, their observed activity levels, and validated energy constants for each activity level). Additionally, an associated environmental inventory can provide information on area characteristics such as location, type, size, surface area, and structural enhancements.

\section{Sample PA Contexts}

In 1985, I became involved in studying PA as part of public health and have been a part National Institutes of Health (NIH) supported projects ever since. During my first study we observed Anglo- and Mexican-American families in their homes using BEACHES-Behaviors of Eating and Activity Children's Evaluation Study (McKenzie, Sallis, Patterson et al., 1991). We assessed PA and food ingestion relative to parent and peer prompts and consequences during both baseline and intervention periods. Later we investigated the generalizability of the intervention by taking both intervention and control families to the San Diego Zoo where their PA and eating behaviors were assessed in a novel setting.

After that study, we began doing PA interventions in schools. The most prominent of these was a 7-year study (SPARK-Sports, Play, and Active Recreation for Kids) (McKenzie et al., 2016) which was funded by the National Institutes of Health $(\mathrm{NIH})$ and included schools being assigned randomly to treatment conditions. Later we extended the research into secondary schools (McKenzie et al., 2016; Sallis et al., 2003). SPARK still continues, and is in its thirtyfirst year of being disseminating nationally and internationally (see sparkpe.org). Meanwhile, our extensive work in studying PA in park and recreation settings began in 2002 (McKenzie et al., 2006) and it still continues (e.g., Cohen et al., 2020).

Community Collaborations. I want to emphasize the importance of conducting PA research that is useful and can be disseminated broadly. While elaborate statistics may identify small differences among variables, those findings may not necessarily be useful in bringing about changes. It is important that we translate our research for policymakers and for people that influence them and to remember that not all research is designed for publication. Below are brief descriptions of three projects I was/am involved in that had/have practical importance.

In the first project I trained physical education supervisors in school districts to use SOFIT to assess PE classes and they used the tool to observe 1582 lessons during regular visits to schools. Unfortunately, the data showed PA during lessons was far below recommended levels. Additionally, a large number of lessons ( $n=212$ ) that they went to observe were never conducted. The primary reasons for classes not being held were that the regular PE teacher was not available and there was no substitute (24\%), special school events (20\%), other academic priorities (20\%), and holiday celebrations (19\%). Fortunately, the data collected by the supervisors resulted in staff development and curricular and policy changes within in the districts. 
| 2020 | Volume 1 | Issue 1 | The Journal of Health, Sports, and Kinesiology |

The second example involves OPEN (Observing Park Environments in Nevada), a partnership between the University of Nevada, Las Vegas (UNLV), City of Las Vegas, and Clark County. Under the direction of Monica Lounsbery, UNLV provided leadership and conducted observer training and focus groups while the city officials selected parks in low-income areas and assigned 22 staff to use SOPARC as part of their workload. The staff observed 238 different PA areas in the parks for user (i.e., number, gender, age, PA levels) and area characteristics during three temperature seasons. Assessors, who made 11,424 area visits and observed 33,362 individuals, found differences in use by park location (geography, population density), day of week, time of day, season, and facility type. Most park users were adults (37\%), with $26 \%$ being children, $21 \%$ teens, and $6 \%$ seniors. More males than females at all age levels were seen in the parks (overall, 61 vs. 39\%) and they were more physically active. Areas were usually accessible (98\%) and useable (94\%), but they were rarely supervised (4\%) or had organized activities (5\%). In summary, park staff accrued objective data on patron behavior and on facility use that assisted them in making policy and program changes. As well, they were trained to collect data they could use in other projects. This project, which received unprecedented visibility among policy makers, illustrates the value of building research partnerships.

The third example is a project we just initiated in August. Given concerns related to the COVID-19 pandemic and with support from the National Institutes of Health, we modified SOPARC to create SOMAD (System for Observing Mask Adherence and Distancing). We are using it in two large studies. The first is currently taking place in Philadelphia (SOMAD REPORT, 2020) and the second will involve observations throughout the U.S.. In August, 2020, nearly 5000 individuals were observed in 30 different Philadelphia sites, and preliminary analyses indicate there were disparities in mask use by city district and area type (i.e., commercial streets, playgrounds, parks). There were also differences in mask use by gender, age, and race/ethnicity groupings and by PA levels. For example, while $43 \%$ of the people observed were wearing masks appropriately only about $23 \%$ of those engaged in vigorous activity did. This project shows, once again, how collaborations using systematic observation in the field can be useful in helping agencies/communities plan for creating a healthier society.

\section{Closure}

In closing, I want to reiterate the importance of PA to public health, and I believe there are ways IOHSK members can become more involved in this endeavor. One way is to work together with others--and in terms of collaboration, the World Health organization has a new global action plan to promote physical activity (WHO, 2018). This plan was developed through an extensive worldwide consultation process involving governments and stakeholders from diverse sectors including health, sports, transport, urban design, civil society, academia, and private business. The plan identifies the importance of global leadership and strong regional and national coordination as well as the need for society to increasingly support the notion of all people being physically active across their life spans. Specifically, IOHSK could conduct trans-disciplinary meetings to engender academic discourse related to PA promotion and the organization's sub-disciplines.

Meanwhile, at the local level many parents are not yet attuned to the importance of PA. Even in schools, settings where children and adolescents accrue about $25 \%$ of their PA on days they have PE, do little to promote PA beyond their walls (Kahan, \& McKenzie, 2020). Subsequently, I encourage members to consider what I refer to as the "the bigger bang theory"- the notion that we can make greatest contributions by focusing on policy changes that affect all people within a particular setting, not just simply targeting individuals (McKenzie, 2019). In doing so, we need to be mindful that policies exist at different levels and with different language strengths (e.g., "should" vs. "will") and levels of formalization and accountability. I hope IOHSK members will help develop and implement strongly worded PA policies that start at the top level of their organizations (e.g., government, education, corporate) and ensure ample accountability measures are built in.

Finally, and once again, I am thoroughly honored to have been selected the first-ever distinguished IOHSK lecturer. I look forward to future meetings and to reading about your successes in your journal. For references to my other works, see my website (thomckenzie.com). 
| 2020 | Volume 1 | Issue 1 | The Journal of Health, Sports, and Kinesiology |

\section{References}

Aubert, S., Barnes, J. D., Abdeta, C., Abi Nader, P., Adeniyi, A. F., Aguilar-Farias, N., ...Tremblay, M. S. (2018). Global Matrix 3.0 physical activity report card grades for children and youth: Results and analysis from 49 countries. Journal of Physical Activity and Health, 15(Suppl. 2), S251-S273. doi: 10.1123/jpah.2018-0472

Cohen, D. A., Han, B., Williamson, S., Nagel, C, McKenzie, T. L., Evenson, K. R., \& Harnik, P. (2020). Playground features and physical activity in U.S. neighborhood parks. Preventive Medicine, 131, Article 105945.

Evenson K., Jones, S., Holliday, K. Cohen, D., \& McKenzie, T. L. (2016). Park characteristics, use, and physical activity: A review of studies Using SOPARC (System for Observing Play and Recreation in Communities), Preventive Medicine, 86, 153-166. http://dx.doi.org/10.1016/j.ypmed.2016.02.029

Gipson, M., McKenzie, T. L., \& Lowe, S. (1989). The sport psychology program of the USA Women's National Volleyball Team. The Sport Psychologist, 3, 330-339.

Kahan, D., \& McKenzie, T. L. (2020). Website representations of physical education and physical activity: Comparison of public charter and private schools. Research Quarterly for Exercise and Sport. (Online July 13.) doi: 10.1080/02701367.2020.1761934

Katzmarzyk, P. T., Denstel, K. D., Beals, K., Carlson, J., Crouter, S. E, McKenzie, T. L., Pate, R. R., et al. (2018). Results from the United States 2018 Report Card on Physical Activity for Children and Youth. Journal of Physical Activity and Health, 15(Suppl 2): S422-S424.

McKenzie, T. L. (1986). A behaviorally-oriented residential camping program for obese children and adolescents. Education and Treatment of Children, 9(1), 38-46.

McKenzie, T. L. (2016). Context matters: Systematic observation of place-based physical activity. Research Quarterly for Exercise and Sport, 87(4), 334-341. doi.10.1080/02701367.2016.1234302

McKenzie, T. L. (2019). Physical activity within school contexts: The bigger bang theory. Kinesiology Review, 8(1), 4853. doi: 10.1123/kr.2018-0057

McKenzie, T. L., \& Smith, N. J. (2017). Studies of physical education in the United States using SOFIT: A Review. Research Quarterly for Exercise and Sport, 88 (4), 492-502. doi:10.1080/02701367.2017.1376028

McKenzie, T. L., \& van der Mars, H. (2015). Top 10 research questions related to assessing physical activity and its contexts using systematic observation. Research Quarterly for Exercise and Sport, 86(1), 13-29. doi:10.1080/02701367.2015.991264

McKenzie, T. L., Cohen, D. A., Sehgal, A., Williamson, S., \& Golinelli, D. (2006). System for Observing Play and Recreation in Communities (SOPARC): Reliability and feasibility measures. Journal of Physical Activity and Health, 3(Suppl. 1), S208-222. doi: 10.1123/jpah.3.s1.s208

McKenzie, T. L., Marshall, S. J., Sallis, J. F., \& Conway, T. L. (2000). Leisure time physical activity in school environments: An observational study using SOPLAY. Preventive Medicine, 30, 70-77. doi: 10.1006/pmed.1999.0591

McKenzie, T. L., Sallis, J. F., \& Nader, P. R. (1991). SOFIT: System for observing fitness instruction time. Journal of Teaching in Physical Education, 11, 195-205. doi: 10.1123/jtpe.11.2.195

McKenzie, T. L., Sallis, J. F., Patterson, T. L., Elder, J. P., Berry, C. C., Rupp, J. W., Atkins, C. J., Buono, M. J., \& Nader, P. R. (1991). BEACHES: An observational system for assessing children's eating and physical activity behaviors and associated events. Journal of Applied Behavior Analysis, 24, 141-151. doi: 10.1901/jaba.1991.24-141

McKenzie, T. L., Sallis, J. F., Rosengard, P. R., \& Ballard, K. (2016). The SPARK Programs: A public health model of physical education research and dissemination. Journal of Teaching in Physical Education, 35, 381-389. doi.10.1123/jtpe.2016-0100

Piercy, K. L., Troiano, R. P., Ballard, R. M., Carlson, S. A., Fulton, J. E., Galuska, D. A., ... Olson, R. D. (2018). The physical activity guidelines for Americans. Journal of the American Medical Association, 320, 2020-2028.

Sallis, J. F., McKenzie, T. L., Conway, T. L., Elder, J. P., Prochaska, J. J., Brown, M., Zive, M. M., Marshall, S. J., \& Alcaraz, J. E. (2003). Environmental interventions for eating and physical activity: A randomized controlled trial in middle schools. American Journal of Preventive Medicine, 24, 209-217. PMID: 12657338

Smith, N. J., McKenzie, T. L., \& Hammons, A. J. (2019). International studies of physical education using SOFIT: A review. Advances in Physical Education, 9, 53-74. doi:10.4236/ape.2019.91005

SOMAD REPORT: Systematic Observation of Mask Adherence and Distancing. (2020, September). Studio Ludio, Philadelphia, Pennsylvania, USA.

Trust for America's Health (2020, September). The state of obesity: Better policies for a healthier America 2020. Available at: tfah.org/stateofobesity2020.

U. S. Department of Health and Human Services [USDHHS]. (1996). Physical activity and health: A report of the Surgeon General. Atlanta, GA: Centers for Disease Control and Prevention.

U. S. Department of Health and Human Services. [USDHHS]. (2000). Healthy People 2010 (2nd ed.), Washington, DC: US Government Printing Office. 
| 2020 | Volume 1 | Issue 1 | The Journal of Health, Sports, and Kinesiology |

WHO (2010). Global recommendations on physical activity for health. Geneva: World Health Organization.

WHO (2018). Global action plan on physical activity 2018-2030: More active people for a healthier world. Geneva: World Health Organization. Available in seven languages at:

https://www.who.int/publications/i/item/9789241514187

(CC) (2020. This work is licensed under a CC BY-NC-SA 4.0 International license.

This is an open access article distributed under the Creative Commons Attribution License which permits unrestricted use, distribution, and reproduction in any medium, provided the original work is properly cited.

\section{Journal of Health Sports \& Kinesiology | ISSN 2692-9864 | www.johsk.com}

Page | 8 